known nutritional and disease status". The function of such centres is to provide breeding stock for sub-cultiva. tion elsewhere. To enlarge on these primary type colony centres, they can be organized on the basis of national centres that are usually controlled by official bodies. Such organizations exist at the present time in about a dozen countries, and will soon be found in more. The staff of these centres must include scientists as well as properly trained technicians, in order to apply all the required controls to the animal colonies under their care.

This kind of operation is necessarily costly: for this reason each primary type colony is usually limited to about 100 pairs of animals. Animals produced in these centres are not used directly for experimentation, but as breeding nuclei of high value, from which it is possible to create mass production units, where animals not essentially differing from the strictly controlled animals of the original primary type colony may be produced. This implies that these units should not breed away more than a few generations from the primary type colony, in other words that each production unit should regularly get new breeding stock from the primary type colony centre. This policy is the best safeguard against possible deviation and differentiation from the original defined stock. From the point of view of geneties, such a system prevents the splitting up of major strains into sub-strains that, after a few generations, will be more or less different from the mother strain. From the point of view of health status, primary type colonies are also a necessity. Because of the considerable expenditure in the way of competence and resources for the production of gnotobiotic animals, efforts must be concentrated on primary type colony centres, in order to provide laboratories with all the necessary means (isolators, competent staff, etc.) for keeping nuclei of gnotobiotes of different species and strains. Such nuclei will give any animal unit engaged in production the possibility of rebuilding regularly, if occasion demands, its different colonies from animals with defined flora. As at present conducted, recontamination with undesirable micro-organisms is not a rare event in large production units run under so-called specific pathogen-free conditions; through faulty technique or, frequently enough, through contact with animal technicians. Gradually a colony will build up a flora of its own, different from what it was in the original stock and different from that in other colonies.

Production units have to run on economic lines and can eventually make money if they provide animals to other laboratories, whereas primary type colony centres cannot be expected to be self-supporting. Their operation is a costly enterprise on account of the variety of strict controls that have to be applied to these animals, and of the refined. techniques and the highly competent staff needed. In addition, in most cases, national primary type colony centres have to maintain an inconveniently large number of strains of different species, many of which are infrequently demanded. On account of these stringent requirements for conformity with specification, very few national centres, not to say none, in existence to-day correspond to the definition of an ideal primary type colony centre.

Out of this discussion arises the question of the necessity for a few regional centres, run on an international basis with powerful financial means. An international centre should be able to provide any national centro in the area covered by its activity with breeding nuclei of speci. fied animals of all strains of different species. It should carry on large research programmes, mainly in the fields of research relevant to the production of high-quality animals: geneties, nutrition, pathology, as well as hus. bandry in general that includes, as well as the care of the animal, both the influence and control of its environment. Finally, an international centre should provide suitable training, particularly for scientists aspiring to take charge of animal divisions (national centres or production units), especially in genetics as applied to laboratory animals, and in the new techniques of germ-free life.

In line with other fields of research, this new field, called 'laboratory animal seience', cannot develop without international co-operation. Progress realized in the field of laboratory animals in different parts of the world can only be fragmentary, but it can be accelerated and generalized through intense international contacts, exchange of scientists through scholarships, exchange of consultants, publications, meetings. All these activities directed at international co-operation are, in fact, being pursued by the International Committee on Laboratory Animals. This organization has been able, since 1957, to work along these lines through the generous support of the most important organizations: the World Health Organization, the United Nations Educational, Scientific and Cultural Organization, and also the International Union of Biological Sciences, the Council for International Organization of Medical Sciences, the International Union of Physiological Sciences, the International Union Against Cancer and the International Union of Biochemistry.

To summarize the present trends concerning the provision of laboratory animals, it may be said that there is an increasing demand for defined laboratory animals. Quality controls are necessary for which competent scientists and fully trained technicians are indispensable. In addition, more elaborate facilities are necessary to create an optimum constant environment. Consequently the cost of laboratory animals of the future will definitely increase, and more provision will have to be made in the budgets of research laboratories under the heading of laboratory animals.

Standardized specifications for laboratory animals are conceivable only through some degree of centralization. For this reason, official centres breeding animal stocks in conformity with specification are necessary. International primary type colony centres could be created, and national centres are being developed. In some countries, large production stations will be equipped to produce experimental animals on an industrial basis.

Public health is the concern of the whole of humanity, and is entirely dependent on progress made in biological and medical research. Laboratory animals are the raw material on which these sciences are working. It is, therefore, of vital importance for the advancement of medical knowledge that large numbers of high-quality laboratory animals be produced. This is an international problem.

M. A. SABOURDY

${ }^{1}$ Living Animal Material for Biological Research. Proc. Intern. Comm. Lab. Animals Symp., edit. by Lane-Petter. W. (International Committee on Laboratory Animals, Carshalton, 1958)

${ }^{2}$ The Problems of Laboratory Animal Disease. Proc. Second Intern. Comm. Lab. Animals Symp., edit. by Harris, R. J. C. (Academic Press, London, 1962).

${ }^{3}$ Patterson, J. S., Quality in Laboratory A nimals, Laboratory Animals Centre Collected Papers, 8, 5 (1959).

\title{
PUBLIC HEALTH AND OUTPATIENT NURSING
}

TMPORTANT among the many publications of the World Health Organization are its Public Health
Papers, which publish, for the general public, papers which have been prepared for the Organization on particular health questions. One of these questions-the shortage of well-trained nurses and the problem of how our hospitals should be staffed-is a serious matter in almost every country in the world. In Public Health 
Paper No. 21, entitled The Staffing of Public Health and Outpatient Nursing Services, Methods of Study*, Miss Doris E. Roberts, Nurse Consultant to the United States Public Health Service, has tackled the social and other complex factors involved.

Emphasizing the health services for patients who are not in hospital, Miss Roberts has produced a guide to methods of study of the problem which is designed to help all kinds of public health services, including hospitals, to determine the number and composition of the nursing staff they will require in order to provide efficient and economical nursing for the communities they serve. Successive chapters deal with the principles of staffing, factors which influence the pattern of staffing and methods of estimating the staff requirements. Examples are givon of the forms used for the study of time and activity involved and the progress of patients, and one section

* World Health Organization. Public Health Papers No. 21: The Staffing of Public Health and Outpatient Nursing Services. By Doris E. Roberts Pp. 101. (Geneva: World Health Organization; London: H.M.S.O.,
1963.) 4 Sw. francs; $68.8 d$.; 1.25 dollars. gives a useful guide to the establishment of nursing services where these do not exist. A bibliography completes a useful and well-printed monograph which should be useful to all who have these difficult problems in hand.

Analyses of the financial cost of the kind of planning suggested and of the total cost of the services provided were apparently not within the scope of this enquiry. Nor was the difficult problem of the recruitment of nurses, nor the inadequate salaries paid for the devoted and essential services that nurses render. Everyone who has worked in a hospital, or has been in one as a patient, will surely agree that nurses of all grades should be paid much more than they can, even in these days of high wages, expect. Hospitals could not function without their nursing staff, and it should bo recognized, without delay, that the nursing profossion is a highly skilled vocation which should be rewarded with salaries that are commensurate with the devoted services performed.

G. LAPAGE

\title{
UNIFORM METHODS OF SUGAR ANALYSIS
}

\begin{abstract}
$7 \mathrm{HE}$ origin of the International Commission for Uniform Methods of Sugar Analysis goes back to 1897 when an international meeting was convened in Hamburg in order to attempt to smooth out differences which had arisen in international trade over the determination of the sugar content in raw sugar. It soon became obvious that a standardization of methods of analysis would have to come first and this led to the foundation of the International Commission, to which twenty-one countries were affiliated in 1962 .

Progress in science and technology makes it necessary for a permanent organization to review the position from time to time and to recommend improved definitions and methods for use in the laboratories of the sugar industry. Despite the efforts of the International Commission for Uniform Methods of Sugar Analysis over many years, the situation is characterized by the following quotation from the report of the proceedings of the thirteenth session*, concerning "Ash" (p. 7): "Uniformity in expressing results is obviously lacking, and although local customs and preference are strong factors it is felt that this 13th Session should strongly stress the desirability of endeavouring to attain uniformity". This situation is
\end{abstract}

further illuminated in the discussion of such an important subject as "Reducing Sugars" (p. 15): "the difficulty is pointed out of having too many ICUMSA methods . . . , it was about time to reduce the number . . . and to put an end to the reigning confusion; . . . it was often very difficult to recommend definitely one method to the exelusion of all other methods; . . . it is proposed that an additional recommendation be made to inaugurate studies for the purpose of a possible selection of official methods".

While battling with these general difficulties, the report deals with many specific problems under 29 subject headings, and it is probably true to say that, whereas highly accurate analyses are possible, the methods are often too cumbersome for routine application and in many cases "sampling presents the most difficult problem" (p. 113).

J. EISNER

* International Commission for Uniform Methods of Sugar Analysis. Report of the Proceedings of the Thirteenth Session held at the University of Iramburg and at the Atlantic Hotel, Hamburg, Germany, from August 26 to August 31, 1962. Pp. vii +125. (Keston, Kent : International Commission for Uniform Methods of Sugar Analysis; Paris: Syndicat National de Fabricants de Sucre de France; New York: Sugar Research Foundation Inc., 1963.) $28 \mathrm{~s}$.; $19 \mathrm{NF} ; 4$ dollars.

\section{OPTICAL AND IONOSPHERIC OBSERVATIONS ON THE ACTIVITY OF THE SOLAR CENTRE OF SEPTEMBER 1963}

\author{
By Prof. M. ANASTASSIADIS, Dr. D. ILIAS and Dr. C. CAROUBALOS \\ lonospheric Institute
}

AND

\author{
Dr. C. MACRIS and D. P. ELIAS
}

Astronomical Institute, National Observatory of Athens

\begin{abstract}
GOLLOWING a period of relative calm, intense solar activity occurred during the period September 13--30, 1963. In this article we report briefly the optical and radioelectric observations as well as certain geophysical observations carried out at the National Observatory of Athens, comparing them, where possible, with those of November 1960 (ref. 1) and discussing the most typical observed events.
\end{abstract}

A solar activity centre appeared on the west limb on Septembor 13 at about 1500 U.T. $\left(B=12 \cdot 6^{\circ}\right.$ N., $\mathrm{L}=311^{\circ}$, Mac Math region 6964) while an older centre was developing on the solar disk $\left(B=105^{\circ}, \mathrm{L}=90^{\circ}\right.$, Mac Math region 6961). Centre 6964 reached a maximum area on September 21 estimated at $1190 \times 10^{-6}$ of the surface of the solar hemisphere. Its optical configuration was of type $H$ and it had a 'plage filament'. The microwave 